\title{
PENATAAN ORGANISASI PUSAT PERAGAAN ILMU PENGETAHUAN DAN TEKNOLOGI DENGAN PENDEKATAN TEORI MINTZBERG
}

\author{
Karya Subarman \\ Dosen Fakultas Teknik Prodi Teknik Industri Universitas Pamulang \\ karya_subarman@yahoo.co.id
}

\begin{abstract}
ABSTRAK
Pusat Peragaan Ilmu Pengetahuan dan Teknologi (PP-IPTEK) adalah science center atau wahana pembudayaan Iptek non formal untuk masyarakat umum khususnya peserta didik melalui media alat peraga sentuh-mainkan (hands-on interactive) dan pendidikan sains (educational program). PP-IPTEK berlokasi di Taman Mini Indonesia Indah (TMII), status kelembagaannya adalah satuan kerja yang berada dilingkungan Kementerian Riset, Teknologi dan Pendidikan Tinggi serta manajemen keuangannya menerapkan pengelolaan keuangan yang fleksibel dengan menonjolkan produktivitas, efisiensi dan efektivitas atau dikenal dengan istilah Badan Layanan Umum. Upaya PP-IPTEK dalam membudayakan Iptek belum optimal karena dihadapkan pada kondisi keterbatasan kapasitas serta beban kerja yang belum ditunjang oleh struktur organisasi yang ada saat ini.PP-IPTEK sebagai enterprise the goverment perlu melakukan upaya pembaharuan penataan organisasi dengan memasukkan unsur pengembangan layanan untuk meningkatkan koordinasi dan kemitraan strategis agar PP-IPTEK senantiasa dapat mengakomodasi perkembangan Iptek, kebutuhan masyarakat serta pembudayaan Iptek yang merata keseluruh wilayah di Indonesia. Penataan organisasi menggunakan analisa konfigurasi organisasi dari teori Henry Mintzberg. Hasil analisis bahwa struktur organisasi model machine bureaucrazi dari Henry Mintzberg dapat diimplementasikan untuk penataan organisasi PP-IPTEK yang baru, mengingat model tersebut dianggap cocok dan relevan dengan kultur birokrasi di Indonesia serta dapat mengakomodasi peningkatan pengembangan layanan, penguatan kerjasama dan kemitraan strategis dengan seluruh pemangku kepentingan (stakeholders) PP-IPTEK.
\end{abstract}

Kata kunci: penataan, organisasi, Henry Mintzberg

\section{PENDAHULUAN}

Pendirian Pusat Peragaan Ilmu Pengetahuan dan Teknologi (PP-IPTEK) telah digagas pada tahun1984 oleh Prof. Dr.B.J Habibie yang merupakan salah satu wahana untuk mewujudkan masyarakat yang kreatif, inovatif serta renponsif terhadap kemajuan Iptek, dengan menumbuhkembangkan budaya Iptekdi masyarakat sejak dini, melalui sarana pembelajaran luar sekolah (alat peraga interaktif dan program-program pendukungnya) yang mudah, menghibur, berkesan dan kreatif. Selain itu, PP-IPTEK dibangun dengan maksud untuk menyadarkan masyarakat mengenai perkembangan Iptek dunia yang terjadisangat cepat. Arah perkembangan ini harus disadari agar kita dapat mengikutinya untuk kemudian maju bersama perkembangan tersebut.
PP-IPTEK adalah satuan kerja yang ada dilingkungan Kementerian Riset, Teknologi dan Pendidikan Tinggi, dimana pada tahun 2007 ditetapkan sebagai satker yang menerapkan Pola Pengelolaan Keuangan Badan Layanan Umum (BLU) oleh Kementerian Keuangan. Konsekuensi bagi PPIPTEK yang menerapkan PK-BLU, maka PPIPTEK dituntut untuk terus meningkatkan kuantitas maupun kualitas layanannya.

Capaian-capaian PP-IPTEK masih dirasakan belum optimal dikaitkan dengan citacita luhur nasional untuk membangun dan mencerdaskan seluruh anak bangsa. Upaya PPIPTEK dalam membudayakan Iptek dan inovasi serta mendiseminasikan Iptek dan inovasi belum mencapai seluruh Indonesia. Hal ini disebabkan karena PP-IPTEK dihadapkan pada kondisi keterbatasan kapasitas serta beban 
kerja yang belum ditunjang oleh struktur kelembagaan yang saat ini ada

Oleh karena itu, PP-IPTEK perlu melakukan upaya pembaharuan penataan organisasi dan tata laksana PP-IPTEK dengan memasukan unsur pengembangan layanan, pembangunan koordinasi dan kemitraan strategis agar PP-IPTEK senantia dapat mengakomodasi perkembangan Iptek, kebutuhan masyarakat serta pembudayaan Iptek yang merata keseluruh wilayah Indonesia.

\section{DASAR TEORI}

\section{A. Teori organisasi Mintzberg}

Menurut Henry Mintzberg dalam menciptakan suatu desain organisasi yang efektif, maka mengemukakan pendapatnya yang ditulis dalam sebuah buku Structur In Five: Designing Effective Organization. Buku ini menjelaskan bagaimana organisasi dibentuk dari beberapa elemen untuk menjadi suatu konfigurasi/struktur yang efektif. Dalam bukunya, Mintzberg menyatakan bahwa terdapat lima elemen dasar penyusun organisasi yang meliputi:

1. The Strategic Apex. Manajer tingkat puncak, yang diberi tanggung jawab keseluruhan untuk organisasi tersebut. Dia menjamin agar organisasi menjalankan misi perusahaan yang telah digariskan.

2. The Middle Line. Para manajer yang menjadi penghubung operating core dengan strategic apex

3. The Technostucture. Para analis yang mempunyai tanggung jawab untuk melaksanakan bentuk standarisasi tertentu dalam organisasi

4. The Support Staff. Orang-orang yang mengisi unit staff, yang memberi jasa pendukung tidak langsung kepada organisasi.

5. The Operating Core. Yaitu para pegawai yang melaksanakan pekerjaan dasar yang berhubungan dengan produksi dan jasa

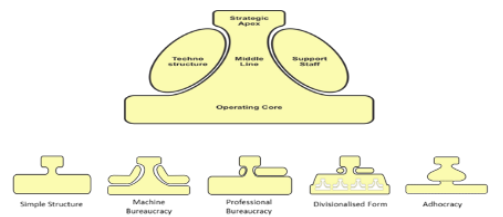

(Sumber: Henry Mintzberg, Structure in Five :

Designing Efective Organization)

Gambar 1 Model Struktur Organisasi Mintzberg
Gambar 1 menunjukkan 5 desain konfigurasi organisasi menurut Henry Mintzberg yang terdiri dari 5 jenis yakni:

\section{a. Simple Structure}

Simple stucture pada umumnya tidak mempunyai technostructure (kalaupun ada hanyalah sedikit), sedikit staf pendukung, pembagian kerja yang tidak kaku dan hirarki manajerial yang kecil. Penggunaan perencanaan, pelatihan, dan perantara juga sangatlah minimal.

b. Machine Bureaucracy

Machine bureaucracy mempunyai tugas operasi rutin yang sangat tinggi, peraturan yang sangat diformalisasi, tugas yang dikelompokkan kedalam departemen fungsional, wewenang yang disentralisasi, pengambilan keputusan yang mengikuti rantai komando dan sebuah struktur administrasi yang rumit dengan perbedaan yang tajam antara aktivitas lini dan staf. Karakteristik utama dari Machine Bureaucracy adalah obsesinya terhadap kontrol dengan mencoba mengeliminasi semua kemungkinan ketidakpastian, sehingga operasi dapat berjalan dengan lancar tanpa gangguan.

\section{c. Profesional Bureaucracy}

Ledakan ilmu pengetahuan khususnya di Negara Barat membuat Profesional Bureaucracy makin digemari pada tahun 1980-an. Eksploitasi ilmu pengetahuan menciptakan kelas baru dari organisasi yang membutuhkan para profesional untuk menghasilkan produk dan jasa mereka. Hal ni telah menciptakan kebutuhan akan suatu disain organisasi yang menyandarkan diri pada spesialisasi yang didasarkan atas kepemilikan kemampuan individual dan bukan atas dasar pembagian kerja.

\section{d. Divisional Form}

Berbeda dengan konfigurasi lainnya, dalam Divisionalised Form tidak terdapat struktur yang lengkap dari strategic apex ke operating core, tapi lebih kepada sebuah struktur yang melapisi struktur yang lain. Konfigurasi Divisionalised Form berfokus pada hubungan struktural antara headquarters dan divisinya, yaitu antara strategic apex dan bagian manajer middle line. 


\section{e. Adhocracy}

Adhocracy dicirikan oleh diferensiasi horizontal yang tinggi, diferensiasi vertikal yang rendah karena tingkatan administrasi yang banyak akan membatasi kemampuan organisasi untuk melakukan penyesuaian. Kebutuhan akan pengawasan juga adalah minimal karena profesional telah menghayati perannya seperti yang diinginkan oleh manajemen.

Perbedaan antara masing-masing desain konfigurasi organisasi secara sederhana dapat dilihat pada Tabel 1

Tabel 1 Lima Jenis Struktur Organisasi

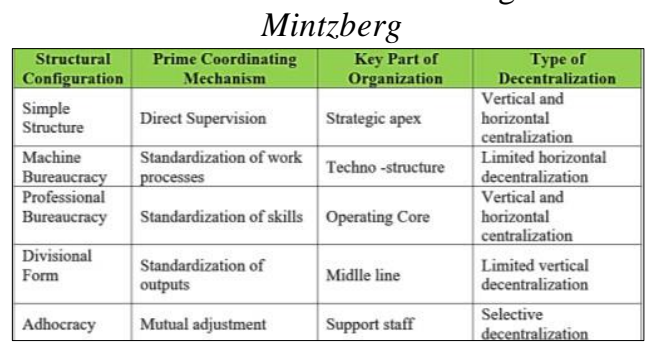

(Sumber: Henry Mintzberg, Structure in Five: Designing Efective Organization)

\section{B. Badan Layanan Umum}

Dalam Peraturan Pemerintah No. 23 Tahun 2005 tentang Pengelolaan Badan Layanan Umum (BLU), definisi dari BLU adalah instansi dilingkungan pemerintah yang dibentuk untuk memberikan pelayanan kepada masyarakat berupa penyediaan barang dan/atau jasa yang dijual tanpa mengutamakan keuntungan dan dalam melakukan kegiatannya didasarkan pada prinsip efisiensi dan efektivitas" atau dalam tata kelola keuangan.

Dari definisi di atas, ada 5 (lima) karakteristik khusus yang membedakan BLU dengan unit organisasi atau instansi pemerintah lainnya, yaitu BLU adalah pemerintah yang memberikan layanan penyediaan barang dan jasa, menjalankan praktek bisnis yang sehat tanpa menerapkan pencarian keuntungan, dijalankan dengan prinsip efisien dan produktivitas dan adanya flexibilitas dan otonomi dalam pengelolaan keuangan.

\section{METODE PENELITIAN}

Penelitian dilakukan dengan menggunakan metode kualitatif deskriptif dengan pendekatan positivis. Tempat penelitian di pusat peragaan Iptek (PP-IPTEK)
- TMII. Teknik pengumpulan data dengan observasi, focus group discussion dengan seluruh pemangku kepentingan (stakeholders), wawancara, pengumpulan dokumen-dokumen dan peraturan-peraturan pemerintah yang berlaku dan studi pustaka. Teknik analisa data dalam penelitian ini dengan mengolah semua data primer maupun sekunder. Hasil pengolahan data yang dianalisa untuk mendapatkan informasi pembaharuan penataan organisasi PP-IPTEK untuk pengembangan kelembagaan dan berguna untuk pimpinan lembaga sebagai pertimbangan pengambilan keputusan.

\section{HASIL DAN PEMBAHASAN}

\section{A. Gambaran Umum PP-IPTEK}

Struktur organisasi PP-IPTEK diatur dalam Peraturan Menteri Negara Riset dan Teknologi Nomor: 10/M/PER/XXI/200. Tentang organisasi dan tata kerja Pusat Peragaan Ilmu Pengetahuan dan Teknologi (Permenristek Nomor 10 Tahun 2006).

Pasal 1 Permenriistek Nomor 10 Tahun 2006 menyatakan bahwa PP-IPTEK adalah unit pelaksana teknis dibidang permasyarakatan dan pembudayaan ilmu pengetahuan dan teknologi yang berada dibawah dan bertanggung jawab kepada Deputi Bidang Pendayagunaan dan Pemasyarakatan Ilmu Pengetahuan dan Teknologi, Kementrian Negara Riset dan Teknologi. PP-IPTEK dipimpin oleh seorang Direktur.

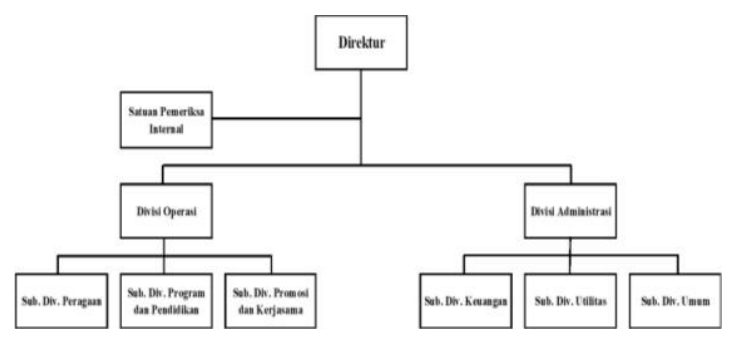

(Sumber: Permenristek Nomor 10/2006)

Gambar 2 Susunan Organisasi PP-IPTEK saat ini

Secara garis besar kegiatan layanan PPIPTEK adalah menyediakan galeri peragaan iptek yang dapat dieksplorasi oleh pengunjung, pengembangan alat peraga dan program sains, kompetisi-kompetisi kreatifitas bagi pelajar, pelatihan sains bagi pendidik, kerjasama dan promosi dengan para pemangku kepentingan (stakeholders) dan memfasilitasi pendirian Pusat Peragaan Iptek di daerah. 


\section{B. Kelembagaan PP-IPTEK}

Pasal Pasal 2 ayat (3) Peraturan Presiden Nomor 7 Tahun 2015 Tentang Organisasi Kementerian Negara menyatakan bahwa Kementerian Riset, Teknologi, dan Pendidikan Tinggi adalah kementerian yang menangani urusan pemerintahan yang ruang lingkupnya disebutkan dalam Undang-Undang Dasar Negara Republik Indonesia Tahun 1945, yang selanjutnya disebut Kementerian Kelompok II.

Pasal 7 ayat (1) Peraturan Presiden Nomor 7 Tahun 2015 menyatakan bahwa susunan organisasi Kementerian Kelompok II terdiri atas unsur pemimpin, pembantu pemimpin, pelaksana, pengawas dan pendukung.

Pasal 21 Peraturan Presiden Nomor 7

Tahun 2015 menyatakan bahwa unsur pendukung dapat berbentuk Badan dan/atau Pusat. Pasal 22 menyatakan bahwa Badan berada di bawah dan bertanggung jawab kepada Menteri dan dipimpin oleh Kepala Badan. Sedangkan Pasal 23 menyatakan bahwa Pusat berada di bawah dan bertanggung jawab kepada Menteri melalui Sekretaris Jenderal dan dipimpin oleh Kepala Pusat

Sebagai tindak lanjut pelaksanaan Peraturan Presiden Nomor 13 Tahun 2015, maka ditetapkan Peraturan Menteri Riset, Teknologi, Dan Pendidikan Tinggi Nomor 15

Tahun 2015 Tentang Organisasi Dan Tata Kerja Kementerian Riset, Teknologi, Dan Pendidikan Tinggi.

Molekuler Eijkman, Pusat Peragaan Ilmu Pengetahuan dan Teknologi, serta lembaga lain yang ditetapkan kemudian, bertanggungjawab kepada Menteri, dan pelaksanaan tugasnya dikoordinasikan oleh Sekretaris Jenderal.

Jika merujuk pada pelaksanaan tugas yang dikoordinasikan oleh Sekretaris Jenderal, maka PP-IPTEKdapat dikategorikan sebagai unsur pendukung di Kementerian Riset, Teknologi, dan Pendidikan Tinggi. Dalam Perpres 7 Tahun 2015 tentang Organisasi Kementerian Negara, Pasal 21 menyebutkan bahwa unsur pendukung Kementerian dapat berupa Pusat atau Badan

Sampai saat ini, dasar hukum yang masih digunakan dalam menjalankan tugas dan fungsi PP-IPTEK adalah Peraturan Menteri Negara Riset dan Teknologi Nomor 10/M/PER/XII/2006 tentang Organisasi dan Tata Kerja Pusat Peraga Ilmu Pengetahuan dan Teknologi.Dalam Pasal 1 Peraturan Menteri tersebut dinyatakan bahwa PP-IPTEK adalah Unit Pelaksana Teknis (UPT) dibidang pemasyarakatan dan pembudayaan ilmu pengetahuan dan teknologi yang berada dibawah dan bertanggung jawab kepada Deputi Bidang Pendayagunaan dan Pemasyarakatan Ilmu Pengetahuan dan Teknologi, Kementrian Negara Riset dan Teknologi.

Bentuk Unit Pelaksana Teknis (UPT) tersebut sudah tidak tepat mengingat dalam Peraturan Menteri Riset, Teknologi, dan Pendidikan Tinggi Nomor 15 Tahun 2015 menegaskan bahwa PP-IPTEK bertanggungjawab kepada Menteri dan pelaksanaan tugasnya dikoordinasikan oleh Sekretaris Jenderal. Ada mandat yang lebih luas yang diberikan, dimana

PP-IPTEK tidak lagi berada di bawah satu Deputi dan hanya mendukung tugas fungsi di satu Deputi tersebut, namun mendukung pelaksanaan tugas fungsi Kementerian. Artinya PP-IPTEK saat ini merupakan unit penunjang Kementerian yang melayani seluruh unit organisasi baik itu Direktorat Jenderal, Sekretariat Jenderal, dan seluruh unit organisasi yang ada di Kementerian termasuk juga Perguruan Tinggi. Karenanya harus ada perubahan yang cukup mendasar terhadap bentuk kelembagaan serta struktur organisasi PP-IPTEK sehingga Peraturan Menteri Negara Riset dan Teknologi Nomor 10/M/PER/XII/2006 ini sudah tidak relevan.

Sampai saat ini, PP-IPTEK telah melakukan kegiatan untuk mendukung pembentukan jaringan. Promosi dan kerja sama sudah sering dilakukan namun hasilnya masih tidak optimal. Hal ini terjadi karena PPIPTEK tidak didukung oleh unit organisasi spesifik yang fokus pada bidang pembentukan jaringan. Selain itu, sumber daya yang ada di PPIPTEK masih sangat terbatas. Apalagi saat ini banyak bermunculan wahana inovasi seperti STP (science technology park) maupun science center (Puspa Iptek) di beberapa daerah. PPIPTEK seharusnya mampu menjadi leading sector dalam rangka koordinasi program untuk mengintegrasikan upaya pembudayaan Iptek dan Inovasi.

Sumber daya merupakan faktor yang menentukan kemajuan PP-IPTEK. Dari sisi Sumber Daya Manusia, saat ini terdapat ketidakseimbangan antara beban kerja dengan jumlah pegawai. Beban kerja yang terlalu 
banyak menyebabkan tugas dan fungsi tidak dapat dilaksanakan secara maksimal.

Permasalahan sumber daya juga terjadi akibat adanya gap dimana ada fungsi yang seharusnya dimiliki oleh PP-IPTEK tetapi tidak ada unit organisasi pendukung. Dengan tidak adanya unit organisasi khusus dalam pengembangan usaha maka kegiatan tidak dapat dilaksanakan secara maksimal.

\section{Rencana Pengembangan dan Penataan Organisasi PP-IPTEK}

Berdasarkan analisa terhadap kerangka kelembagaan, sumber daya dan permasalahan, maka perlu difikirkan rencana pengembangan dan perubahan dari kondisi yang selama ini sudah ada. Yang pertama dan utama harus dilakukan adalah melakukan transformasi PPIPTEK dengan melakukan reposisi dan revitalisasi PP-IPTEK sebagai sebuah lembaga.

Dengan menjadikan "Pembudayaan dan Pengembangan Masyarakat yang Inovatif dan menguasai IPTEK" sebagai definisi filosofis (root definition), maka PP-IPTEK diharapkan akan berubah. Perubahan tersebut semestinya bersifat mendasar mulai dari tujuan, strategi yang akan dilakukan serta cara yang dipilih untuk mencapai tujuan tersebut.

Proses tranformasi dapat diwujudkan jika dibangun paradigma baru tentang PPIPTEK. PP-Iptek harus mampu menampilkan image baru, brand baru dan mendapat respon positif sebagai sebuah organisasi yang telah berubah. Untuk itu, perlu dibangun suatu "kepribadian" PP-IPTEK

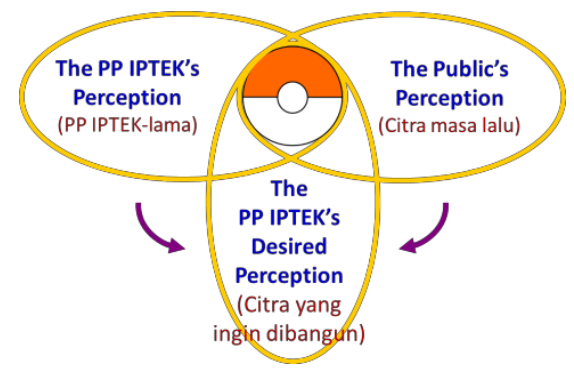

(Sumber: Hasil Pengolahan)

Gambar 3 Membangun Kepribadian PP-IPTEK

Gambar 3 menunjukkan sebuah gambaran mengenai citra yang ingin dibangun oleh PP-IPTEK. PP-IPTEK dengan bentuk organisasi lama harus berubah mulai dari sisi Sumber Daya Manusia, konsep tentang kerangka pendanaan, serta struktur organisasi.
Perubahan nilai-nilai harus dilakukan dari nilai lama dimana terjadi "fragmentasi pengelolaan dalam rangka pembudayaan Iptek" harus diubah menjadi nilai baru dimana dilakukan "konsolidasi nasional pembudayaan dan diseminasi Iptek dan inovasi."

Fragmentasi pengelolaan dalam rangka pembudayaan Iptek mempunyai kondisi dimana PP-IPTEK merupakan Pusat Peragaan IPTEK, adanya potensi nasional yang terfragmentasi, masih berfokus pada display alat peraga dan pengorganisasian PP-IPTEK masih bersifat stand alone

Dengan dilakukan transformasi nilai baru dimana dilakukan konsolidasi nasional pembudayaan dan diseminasi Iptek dan inovasi, maka akan terbentuk kondisidimana PP-IPTEK sebagai Pusat Pembudayaan dan Diseminasi IPTEK dan Inovasi, adanya konsolidasi dan sinergi nasional dalam pengelolaan potensi pusat dan daerah, produk dan jasa sebagai solusi pembudayaan dan desiminasi Iptek dan inovasi dan Pengorganisasian PP-IPTEK sebagai unit mandiri, sekaligus pengelola "holding-type operation" bagi potensi yang ada.

Untuk melakukan transformasi, dapat digunakan analisis CATWOE yang merupakan kepanjangan dari Customer, Actor, Transformation Process, World View, Owner, serta Environment. Pendekatan transformasi IPTEK dapat dilihat pada Gambar 3

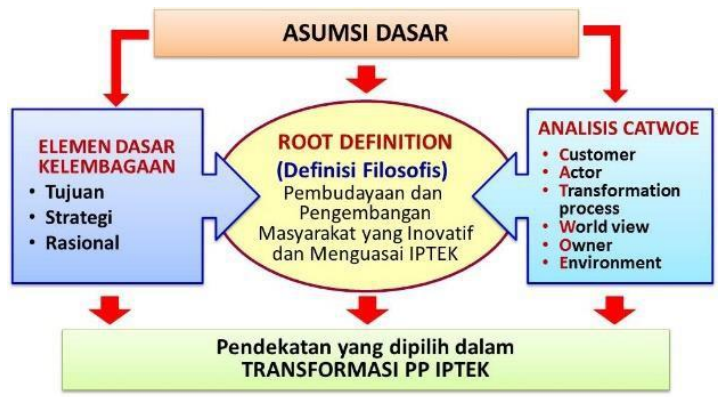

(Sumber: Hasil Pengolahan)

Gambar 4 Kerangka Pikir Wahana Pembudayaan dan Pengembangan Masyarakat yang Inovatif dan Menguasai Iptek

CATWOE adalah mnemonic (tools pengingat) yang membantu mengidentifikasi dan mengkategorikan semua pemangku kepentingan/stakeholders(orang, proses, lingkungan, entitas) berdasarkan 6 (enam) hal, yakni Customers, Actors, Tranformation process, World view, Owner, Environmental Constraints (disingkat CATWOE). Hasil dari analisa sistem dapat digunakan untuk 
merumuskan Root Definition. Root definition atau definisi filosofis, adalah deskripsi terstruktur dari suatu sistem yang menguraikan kegiatan yang berlangsung (atau mungkin terjadi) dalam organisasi yang dipelajari.

Tabel 2 CATWOE Pada Proses Transformasi PP-

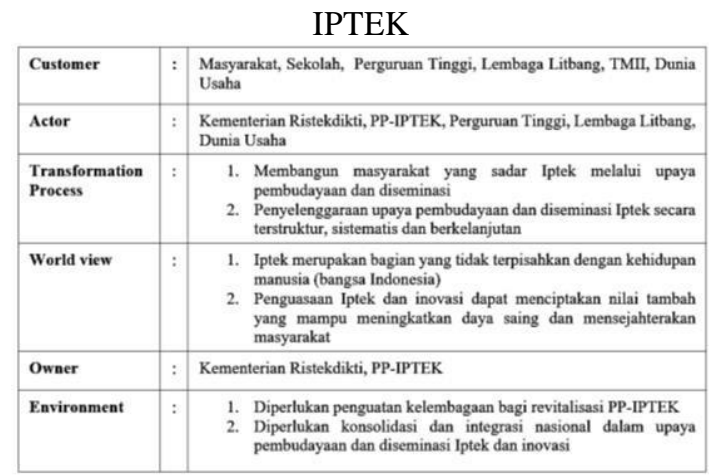

(Sumber: Hasil Pengolahan)

Untuk melakukan perubahan terhadap PP-IPTEK memang bukan hal yang mudah. Tetapi hal ini harus segera dilakukan. Saat ini merupakan momen yang tepat untuk melakukan perubahan dengan pertimbangan bahwa:

1. Bentuk kelembagaan dan struktur organisasi PP-IPTEK harus disesuaikan dengan bentuk yang diatur dalam Peraturan Menteri Riset, Teknologi, dan Pendidikan Tinggi Nomor 15 Tahun 2015 tentang Organisasi dan Tata Kerja Kementerian Riset, Teknologi, dan Pendidikan Tinggi.

2. PP-IPTEK merupakan Badan Layanan Umum (BLU) yang diberi keleluasaan menentukan tarif layanan atas izin Menteri Keuangan. Tarif layanan yang saat ini digunakan mengacu pada Peraturan Menteri Keuangan Nomor 118/PMK.05/2009 tentang Tarif Layanan Badan Layanan Umum Pusat Peragaan Ilmu Pengetahuan dan Teknologi Pada Kementerian Negara Riset dan Teknologi

Pada dasarnya, tujuan dilakukan reposisi dan revitalisasi PP-IPTEK adalah:

1. Terwujudnya birokrasi dan organisasi yang efektif dalam melaksanakan misi pembudayaan dan diseminasi Iptek dan inovasi yang terarah, terpadu dan sistematis di Indonesia;

2. Terbangunnya sinergitas jaringan potensi dan kapabilitas pembudayaan Iptek yang dikelola oleh pemerintah pusat, pemerintah daerah maupun pemangku kepentingan lainnya;
3. Terbangunnya "point of service" layanan pembudayaan Iptek dan inovasi, baik pada tingkat pusat maupun daerah, yang terwujud dari sinergitas jaringan potensi dan kapabilitas pembudayaan Iptek; dan

4. Terwujudnya masyarakat Indonesia yang sadar Iptek, tertarik dan berkemauan untuk melaksanakan penelitan dan berinovasi.

Dengan demikian, maka perlu dilakukan juga perubahan atas visi dan misi PP-IPTEK sebagai berikut:

Tabel 3 Visi dan Misi PP-IPTEK

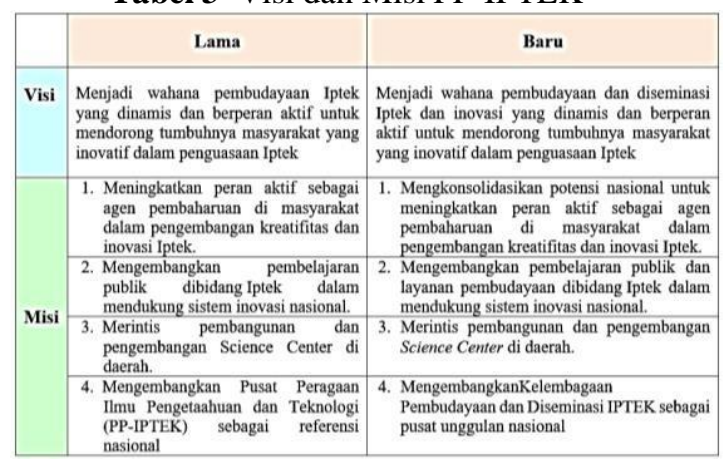

(Sumber: Hasil Pengolahan)

Berdasarkan visi dan misi baru sebagaimana dijabarkan diatas, maka diperlukan penambahan unit baru pada organisasi PP-IPTEK yang akan dibahas lebih lanjut.

Pada hakekatnya konsep pengembangan peragaan dan program harus dilakukan secara terintegrasi dan komprehensif, sehingga penyajian layanan peragaan dan program dilakukan secara bersama dan sebagai satu kesatuan yang utuh. Peragaan dan program bagaikan dua sisi mata uang, yang tidak dapat dipisahkan, saling melengkapi dan memperkuat satu sama lain. Maka dengan demikian maka revitalisasi dan reposisi PPIPTEK yang akan dilakukan haruslah dapat memfasilitasi kebutuhan tatanan organisasi dan peningkatan sumberdaya untuk mendukung pengembangan usaha PP-IPTEK baik pengembangan berupa peragaan, program atau kegiatan lain dalam usaha pembudayaan Iptek di Indonesia.

\section{Pengembangan Struktur Organisasi PP- IPTEK}

Pada dasarnya, struktur organisasi yang digunakan adalah struktur organisasi jenis kedua yaitu machine bureaucracy. Hal ini 
masih dianggap cocok dan relevan dengan kultur birokrasi di Indonesia.

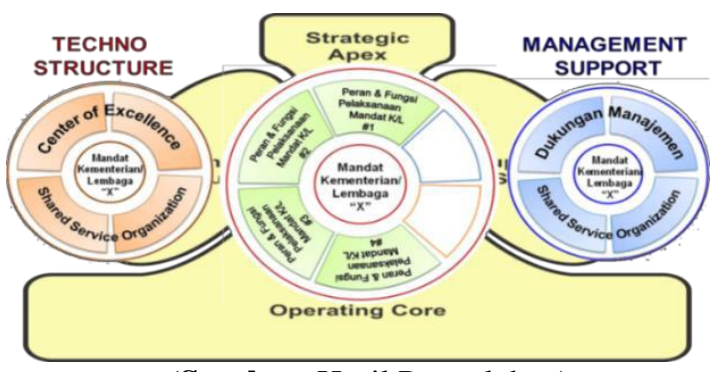

(Sumber: Hasil Pengolahan)

Ganbar 5 Konfigurasi Model Mintzberg Untuk Struktur Organisasi "Machine Bureacuracy"

Berdasarkan kondisi dan rencana pengembangan yang telah disampaikan sebelumnya, penataan organisasi yang dipilih mempunyai ciri-ciri sebagai berikut:

1. Dilengkapi dengan fungsi pengembangan, sekaligus koordinator penyelarasan program dengan potensi wahana inovasi lainnya seperti STP dan Puspa Iptek.

2. Pengembangan portofolio "jasa pembudayaan Iptek". Jasa pembudayaan Iptek yang dimaksud dapat berupa jasa pendampingan pembangunan dan penyiapan peragaan Iptek, jasa pendampingan perencanaan dan pelaksanaan program, kegiatan atau acara khusus terkait pembudayaan maupun jasa pembudayaan Iptek dan inovasi lainnya.

3. Penguatan kerjasama dan kemitraan strategis.

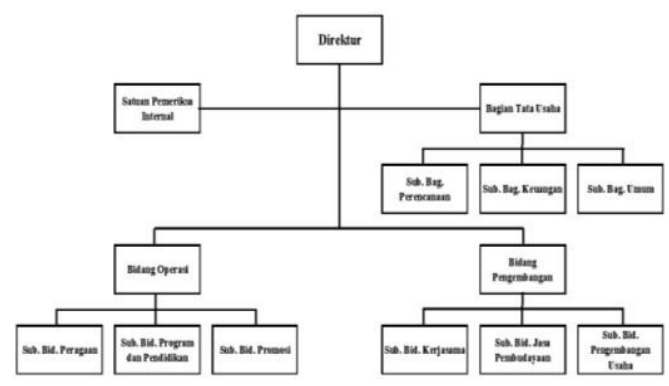

(Sumber: Hasil Pengolahan)

Gambar 6 Pengembangan Organisasi PPIPTEK

Dalam penataan organisasi PP-IPTEK, definisi Pusat Peragaan Ilmu Pengetahuan dan Teknologi (PP-IPTEK) adalah unsur pendukung di bidang pemasyarakatan dan pembudayaan ilmu pengetahuan dan teknologi yang berada di bawah dan bertanggung jawab kepada Menteri Riset, Teknologi, dan Perguruan Tinggi melalui Sekretaris Jenderal Kementerian Riset, Teknologi, dan Perguruan
Tinggi. PP-IPTEK mempunyai tugas melaksanakan pengelolaan di bidang peragaan dan program ilmu pengetahuan dan teknologi dalam rangka membudayakan dan mengembangkan masyarakat yang inovatif dan menguasai ilmu pengetahuan dan teknologi.

\section{KESIMPULAN}

Sebagai unsur penunjang yang mendukung pelaksanaan tugas dan fungsi Kementerian di bidang pemasyarakatan dan pembudayaan ilmu pengetahuan dan teknologi, perlu diadakan penataan struktur organisasi PP-IPTEK dengan menambah beberapa jabatan yang khususnya menangani bidang pengembangan yang ruang lingkup tugasnya meliputi kerjasama, jasa pembudayaan dan pengembangan usaha.

Dengan adanya penambahan bidang pengembangan dalam struktur organisasi, kegiatan pengembangan usaha baik yang dilakukan secara internal PP-IPTEK maupun kerjasama dengan mitra-mitra strategis yang bersifat komprehensif dapat dilaksanakan secara maksimal dan diharapkan akan meningkatkan kinerja layanan PP-IPTEK

\section{DAFTAR PUSTAKA}

Anugrah, I. W., \& Suhaeni, T. (2018). Pengaruh Kepemimpinan Stratejik Terhadap Strategi Bersaing UKM Café dan Restoran. Jurnal Riset Bisnis dan Investasi, 3(3), 78-88

Fanny, S. (2015). Studi Deskriptif Gaya Kepemimpinan PT. X Surabaya. Agora, 3(2), 112-114.

Lukman, Mediya, Badan Layanan Umum dari Birokrasi Menuju Korporasi, PT. Bumi Aksara, 2013

Mintzberg, H. (1989). Mintzberg on management: Inside our strange world of organizations. Simon and Schuster.

Mintzberg, Henry, Structures in Five : Designing Efective Organization, Prentice Hall International Edition, 1993

Pusat Peragaan Iptek, Kementerian-Riset, Teknologi dan Pendidikan Tinggi, 
Laporan Tahunan PP-IPTEK Tahun 2016, 2017

Putra, G. S. A., \& Maulana, N. (2018). Strategi Meningkatkan Daya Saing Industri Kreatif Indonesia: Studi Kasus Pengembangan Klaster Industri Alas Kaki Kecamatan Tamansari, Bogor. Ultima Management: Jurnal lmu Manajemen, 10(2), 97-109.

Utaminingsih, S., \& Candra, A. (2015). Penentuan Lama Waktu Istirahat Berdasarkan Beban Kerja Dengan Menggunakan Pendekatan Fisiologis Disaint JOHN'S SCHOOL BSD.

Teknologi, Jurnal Ilmiah dan teknologi, Fakultas Teknik Dan Fakultas MIPA Universitas Pamulang, 11(29), 1-12.

Zuhal, Visi Iptek Memasuki Milenium II,Penerbit Universitas Indonesia, 2000

Zulziar, M. (2018). ANALISA MATERIAL BAHAN PEMBUAT SENSOR La0. 67Ba0. 33Mn1-xNixO3 DENGAN PENAMBAHAN Ni MENGGUNAKAN FOUR POINT PROBE. TEKNOLOGI: Jurnal Ilmiah dan Teknologi, 1(1), 1-9 